Article

\title{
Assessment of the Worthwhileness of Efficient Driving in Railway Systems with High-Receptivity Power Supplies
}

\author{
Alejandro Cunillera ${ }^{1}$, Adrián Fernández-Rodríguez ${ }^{1} \mathbb{D}$, Asunción P. Cucala ${ }^{1}$, \\ Antonio Fernández-Cardador ${ }^{1}$ and Maria Carmen Falvo ${ }^{2, * \mathbb{D}}$ \\ 1 Institute for Research in Technology, ICAI School of Engineering, Comillas Pontifical University, \\ 23 Alberto Aguilera Street, 28015 Madrid, Spain; Alejandro.Cunillera@iit.comillas.edu (A.C.); \\ Adrian.Fernandez@iit.comillas.edu (A.F.-R.); paloma.cucala@iit.comillas.edu (A.P.C.); \\ Antonio.Fernandez@icai.comillas.edu (A.F.-C.) \\ 2 DIAEE-Electrical Engineering, University of Rome Sapienza, via delle Sette Sale 12b, 00184 Rome, Italy \\ * Correspondence: mariacarmen.falvo@uniroma1.it
}

Received: 16 March 2020; Accepted: 6 April 2020; Published: 10 April 2020

check for updates

\begin{abstract}
Eco-driving is one of the most important strategies for significantly reducing the energy consumption of railways with low investments. It consists of designing a way of driving a train to fulfil a target running time, consuming the minimum amount of energy. Most eco-driving energy savings come from the substitution of some braking periods with coasting periods. Nowadays, modern trains can use regenerative braking to recover the kinetic energy during deceleration phases. Therefore, if the receptivity of the railway system to regenerate energy is high, a question arises: is it worth designing eco-driving speed profiles? This paper assesses the energy benefits that eco-driving can provide in different scenarios to answer this question. Eco-driving is obtained by means of a multi-objective particle swarm optimization algorithm, combined with a detailed train simulator, to obtain realistic results. Eco-driving speed profiles are compared with a standard driving that performs the same running time. Real data from Spanish high-speed lines have been used to analyze the results in two case studies. Stretches fed by $1 \times 25 \mathrm{kV}$ and $2 \times 25 \mathrm{kV}$ AC power supply systems have been considered, as they present high receptivity to regenerate energy. Furthermore, the variations of the two most important factors that affect the regenerative energy usage have been studied: train motors efficiency ratio and catenary resistance. Results indicate that the greater the catenary resistance, the more advantageous eco-driving is. Similarly, the lower the motor efficiency, the greater the energy savings provided by efficient driving. Despite the differences observed in energy savings, the main conclusion is that eco-driving always provides significant energy savings, even in the case of the most receptive power supply network. Therefore, this paper has demonstrated that efforts in improving regenerated energy usage must not neglect the role of eco-driving in railway efficiency.
\end{abstract}

Keywords: railway transport; eco-driving; energy efficiency; optimization algorithm; power systems

\section{Introduction}

Railways are considered an inexpensive, fast and safe transport mode. Furthermore, this transport mode is energy-efficient and its contribution to global warming is less severe compared with others [1]. Despite that, its increasing activity throughout the world [2] makes it necessary to continue working on the energy efficiency of rail transport to achieve a sustainable transport industry without losing sight of service quality improvements.

Eco-driving, also named speed profile optimization or train trajectory optimization, is one of the most important measures with which to achieve significant energy reductions in the energy consumption 
of railway operations. It consists of obtaining a way to drive a train on a journey to fulfil a target running time with minimal energy consumption. Eco-driving has the advantage of being a short-term action that requires low investments, while other measures, such as improving the infrastructure [3-12] or rolling stock [13-17], usually require a significant investment and long/mid-term actions.

The eco-driving problem has been studied since 1968, when Ichikawa applied the Pontryagin's maximum principle to a greatly simplified train dynamics model, to derive the optimal control of a train [18]. Since then, numerous researchers have contributed to the eco-driving field with their proposals.

Control theory $[18,19]$ shows that the optimal speed profile for a train running from two stations in a flat track consists of a sequence of four regimes: maximum traction, cruising, coasting and maximal braking. If the line geometry is more complex [20,21] or the train has regenerative braking [22], the most energy-efficient speed profile results as a smart combination of these four regimes.

In the literature, different optimization techniques have been proposed to find the right combination of the efficient driving regimes. These techniques can be divided into two groups [23]: analytical and numerical methods.

Typically, analytical methods apply the Pontryagin maximum principle to obtain the optimality necessary conditions, and using these results, apply different techniques to find the optimal speed profile. These techniques are: constructive algorithms [20-22,24-26], dynamic programming [27-31], sequential quadratic programming [30,32] and the Lagrange multiplier method over the discretized problem [33]. Other analytical methods are based on transforming the optimal control problem into a non-linear problem and solving it directly [34,35].

Analytical methods are, in most cases, fast procedures that can produce the optimal solution. However, the complexity of the problem must be reduced to apply these methods, due to the requirements for obtaining the analytical solution. This leads to simplifications in the train and line models and in the operational restrictions that the solution must comply.

On the contrary, the use of numerical methods does not demand simplifications in the train and line model, and any model to observe the requirements of passengers' comfort or operation characteristics can be included. In recent years, these methods have received growing attention aimed toward solving the eco-driving problem, because of the improvement of computational performance; in most cases, they are more computationally expensive than analytical procedures.

Different numerical methods have been applied to optimize the energy consumption of train driving: direct search algorithms [36,37], brute force [38], Monte Carlo simulation [39], artificial neural networks [40,41] and nature inspired algorithms [29,42-47]. Among these techniques, nature inspired computational intelligence is one of the most common methods applied to solve the speed profile optimization problem. These techniques provide a framework that can be easily implemented and are independent of the specificities of the problem. Moreover, they can be used in combination with complex train dynamics models that can be easily substituted by other different models when the characteristics of studied railway line change.

Many nature inspired computational intelligence techniques have been proposed in the literature to solve different problems [48]. When looking in detail at the algorithms applied to solve the train eco-driving problem, the following are present: the genetic algorithm (GA) [29,42,47,49-54], the multi-population genetic algorithm (MPGA) [55,56], GA with fuzzy parameters [57-60], differential evolution [46], ant colony optimization [29,61,62], simulated annealing [45,63], the indicator based evolutionary algorithm (IBEA) [64], the non-dominated sorting genetic algorithm II (NSGA-II) [43,44], multi-objective particle swarm optimization (MOPSO) $[44,65]$ and dynamic versions of NSGA-II and MOPSO [66,67].

Apart from the specific technique applied to obtain the efficient train driving, the literature shows consistently that the use of eco-driving provides important energy savings [68]. Typically, trains on mainline railways are manually driven and the whole driving application is made by means of driver advisory systems (DASs). Several works have reported applications of eco-driving in DASs [69-73], 
wherein energy saving between $7 \%$ and $22 \%$ have been obtained. On the other hand, nowadays many urban railways are usually driven automatically by means of automatic train operation (ATO) systems. In these systems, efficient driving commands must be programmed to perform eco-driving speed profiles. Several authors reported applications of eco-driving in ATO systems, wherein energy savings between $6 \%$ and $18 \%$ have been obtained $[44,65,74-76]$.

Savings obtained thanks to eco-driving are mainly due to the substitution of the use of braking by coasting periods. Besides, acceleration phase can optimized to reach higher energy efficiency. Nowadays, most trains are equipped with regenerative braking that allows recovering the kinetic energy during deceleration phases. In DC systems, regenerated energy cannot be totally used because it is necessary to have another train in the system consuming the amount of energy regenerated (except for trains which are equipped with on-board accumulation devices [77]). However, the use of reversible substations $[5,6,8,9]$ allows them to use all the energy regenerated in a DC system by sending the regenerated energy not used by other trains to the utility grid. In modern high-speed systems the electrification is AC and substations allow the flow of energy in both directions (consumption or generation); thus, as in the previous case, it is possible to use all the regenerated energy produced (except electrical losses).

In this context of high use of regenerated energy, a question arises: is it worthwhile to minimize the energy consumption of a train, or will any driving over the same running time provide similar energy consumption?

The research objectives of this work are, on one hand, to assess the effectiveness of eco-driving under different scenarios of regenerated energy receptivity, and on the other hand, to see whether there is a scenario wherein eco-driving presents no relevant efficiency, providing an answer to the previous question.

The studies presented in this paper are based on real data from Spanish high-speed lines. The studied lines have been chosen because they are AC electrified, which offers high regenerated energy usage. The lines selected are Madrid-Barcelona, which is fed by a $2 \times 25 \mathrm{kV}$ power supply system, and Madrid-Sevilla, which is fed by a $1 \times 25 \mathrm{kV}$ power supply system. In the case study, two driving strategies are compared: an optimized eco-driving strategy and a standard driving strategy. The standard driving strategy consists of maintaining a holding speed during the journey to meet the running time. On the other hand, the efficient eco-driving consists of two driving commands: a holding without braking command and a coasting command before the braking up to the arrival station.

A MOPSO (multi objective particle swarm optimization) algorithm [78] combined with a detailed train simulation model [47] has been used in this piece of research to generate not only the efficient driving but also the standard driving for different target running times. This algorithm has the advantage of generating in a single run a set of non-dominated solutions, also known as Pareto front. A non-dominated solution is one that cannot be improved at the same time in all the problem's objectives. In the eco-driving problem, the objectives are the minimization of energy consumption and running time. As these objectives are conflicting, the result of the algorithm is Pareto front of solutions, where each solution is a speed profile with the minimum energy consumption for each possible running time. This way, MOPSO allows one to compare results easily in a wide range of running time values. MOPSO algorithm has demonstrated its suitability to the eco-driving problem in $[44,66,67]$.

The usable regenerated energy that a train can produce depends mainly on two factors: the efficiency ratio of the train motor (that measures the efficiency of the train as a kinetic energy accumulator), and the transmission losses produced at catenary $[30,79,80]$. For this reason, the influences of different realistic values of these factors are analyzed in this paper to provide insights into the benefits provided by eco-driving on these types of lines.

This article is organized as follows: Section 2 describes the simulation model used to evaluate the different speed profiles. Section 3 describes the different driving strategies studied. The manual driving model is described in Section 4. Section 5 introduces the nature-inspired algorithm used 
to obtain the energy-efficient speed profiles. The results obtained and the discussion are shown in Section 6, and Section 7 presents the conclusions of this article.

\section{Train Simulation Model}

In this work, an accurate simulation model is used to calculate the speed profiles of a train and its consumption measured at the pantograph and at substations. It is divided into three modules: train, line and manual driving [47]. The train simulator is a software developed by Comillas Pontifical University researchers. This simulator is a desktop application for Windows coded in an object-oriented environment using the $\mathrm{C}++$ /CLI programming language. A validation against real on-board registered measurements was performed for high-speed trains on commercial services and night tests on the Madrid-Barcelona line, demonstrating its accuracy. Simulation results taken from this software showed an average error of $1.2 \%$ in running time and $0.4 \%$ in energy consumption compared with on-board measurements [47]. This accurate simulator has been applied for the design of efficient driving and tested in collaboration with Renfe and Adif.

The train module includes mass, length, running resistance, adhesion coefficient and the engine characteristics. These are introduced through the maximum traction and braking effort curves, which depend on the train speed. In this work, the traction and braking efficiencies are taken as equal and non-dependent on the train speed. This module includes also the energy consumption of the on-board auxiliary systems and a minimum constant braking effort that is applied along neutral zones in order to feed the auxiliary systems when no braking curve is affecting the train.

The physical characteristics of the line-track geometry (grades, grades transitions and track curves and their transitions), speed limits, tunnels, stopping points, stations, neutral zones, electrical substations and catenary features-are introduced in the line module.

The manual driving module calculates the traction and braking force needed at every time step, taking into account track data, speed limits, the position and speed of the train and stopping points. The driving module takes as input driving commands that can be easily interpreted by a human driver and generates speed profiles. In this work, the human driving is emulated by using a PI (proportional-integral) controller, in which the engine effort is modelled as a variable that represents the proportion of traction or brake that is demanded with respect to the maximum values for the current train speed.

\subsection{Train Dynamics Model}

At every time step the train position $s(t)$, speed $v(t)$ and acceleration $a(t)$ are determined by using Newton's second law Equations (1)-(5),

$$
\begin{gathered}
\frac{d s}{d t}=v(t), \\
\frac{d v}{d t}=a(t), \\
a(t)=\frac{F_{m}(\mathrm{t})-F_{b}(\mathrm{t})-F_{r}(v)-F_{g}(s)}{\rho m} \\
s\left(t_{0}\right)=s_{0}, s\left(t_{f}\right)=s_{f}, \\
v\left(t_{0}\right)=v_{0}, v\left(t_{f}\right)=v_{f},
\end{gathered}
$$

where $m$ is the train mass, $\rho$ is the dimensionless rotating mass factor, $F_{r}(v)$ is the running resistance and $F_{g}(s)$ are the forces that affect the train due to the track geometry. $F_{m}(t)$ is the engine traction force and $F_{b}(t)$ is the braking force. $t_{0}, t_{f}, s_{0}, s_{f}, v_{0}$ and $v_{f}$ are the initial and final times, positions and speeds of the train, respectively.

The engine traction force $F_{m}(t)$ is bounded by a maximum traction curve that depends on the speed of the train. The braking force $F_{b}(t)$ has two components: the electrical or regenerative and the 
pneumatic brakes. The regenerative brake is limited by a maximum electrical braking curve; if the train needs to brake it will use pneumatic brake to complement the electrical when the electrical one is saturated. The manual driving module computes both forces at every simulation time step to control the train dynamics considering the driving commands while obeying speed limits and stopping the train at the stopping points. In neutral zones, a minimum braking effort is applied to feed the auxiliary systems using regenerative energy.

The running resistance $F_{r}(v)$ depends quadratically on the train speed and it is modelled by the Davis formula (Equation (6)):

$$
F_{r}(v)=A+B v+T_{f} C v^{2}
$$

where $A, B$ and $C$ are the Davis formula coefficients. $T_{f}$ is a factor that models the impact of tunnels on the running resistance and it modifies the quadratic term. It is equal to one when the train is outside a tunnel and greater otherwise.

The considered forces on the train due to the track geometry, $F_{g}(s)$, are those due to the track grades and curves:

$$
F_{g}(s)=m g p(s)+m g \frac{K}{R(s)}
$$

where $m$ is the mass of the train; $g$ is the gravity acceleration; $p(s)$ and $R(s)$ are the averages of the grades and curve radius respectively affecting the train in the position $s . K$ is a constant that depends on the gauge of the track which units are the same as $R(s)$ (meters). The gauge in the considered lines is standard UIC (Internal Union of Railways) gauge, $1.435 \mathrm{~m}$, and $K=600$. Notice that the force due to curves is modelled as an equivalent grade.

\subsection{Energy Consumption Model}

The simulation model calculates the power consumed at the pantograph and at the electrical substations at every time step as a function of the train speed and the engine traction or braking effort by using Equations (8) and (9)

$$
\begin{gathered}
P_{\text {pantograph }}=\frac{F_{m} v}{\eta_{t}}+P_{\text {aux }}-\eta_{b} \min \left(F_{b}, F_{\text {max }}(v)\right) v, \\
P_{\text {substations }}=P_{\text {pantograph }}+r(s)\left(\frac{P_{\text {pantograph }}}{V \cos \varphi}\right)^{2}
\end{gathered}
$$

where $\eta_{t}$ is the engine traction efficiency, $\eta_{b}$ is the engine regenerative brake efficiency, and both are considered constant. $P_{a u x}$ is the power consumed by the auxiliary systems; $F_{\max }(v)$ is the maximum regenerative brake force at speed $v \cdot r(s)=\hat{r}\left|s-s_{s s}\right|$ is the resistance of the catenary that depends on the distance between the train and the electrical substation, which is located at position $s_{s s}$. In this article the influence of the lineal resistance $\hat{r}$ on the energy consumption is studied. $V$ is the nominal line voltage and $\cos \varphi$ is the power factor, and they are assumed to be constant. If a train is in a neutral zone, the power consumed at the electrical substations is zero. The energy consumption at the pantograph and substations can be obtained by integrating Equations (8) and (9) in time, respectively. This section may be divided by subheadings. It should provide a concise and precise description of the experimental results and their interpretation, and the experimental conclusions that can be drawn.

\section{Driving Strategies and Commands}

In this work the performances of two driving strategies are compared in terms of energy savings. In particular, a holding speed without braking and final coasting phase eco-driving strategy is compared against a standard driving strategy consisting in holding a constant speed with braking. All the regenerated energy at the pantograph is assumed to be returned to the $\mathrm{AC}$ power grid. The dependence 
of the energy consumption measured at the pantograph and electrical substations on the engine traction and brake efficiency and on the losses at the catenary is analyzed.

For the eco-driving strategy, the journey is divided in two phases. In the first phase, the driver must hold a certain speed by applying traction. If braking is necessary to maintain the constant speed, coasting is applied instead, and thus, the speed of the train will increase. In the second phase, the driver must apply coasting until the train reaches its braking curve to stop at the station.

For the standard strategy, a cruise speed is determined for the whole journey. The driver has to maintain that speed until reaching the braking curve. To drive at a constant speed, braking can be applied if necessary. Any driving strategy has to be described in easily-interpretable commands so that a driver can apply them. The driving commands are defined by using a command vector. It has two components. The first one contains the position $s_{c}$ that corresponds to the final point of the holding speed phase. The holding speed $v_{\mathcal{c}}$ is introduced in the second component. The final coasting phase is performed starting at $s_{c}$ up to the braking curve in the holding speed without braking and the final coasting driving strategy. Notice that speed limits of the line are observed by the driving model braking the train when necessary.

\section{Driving Model}

A closed-loop PI controller is used to emulate the manual driving by controlling the train dynamics. It takes into account the maximum acceleration and service deceleration of the train, the jerk limitation, the maximum tractive effort, the speed limits and the energy that has to be regenerated by braking in neutral zones. The control loop minimizes the difference between an objective speed $v_{o b j}$ and the train speed $v$. At every time step the objective speed is computed in terms of the driving commands and the track speed limits. To do so, the braking curves to the next ceiling speed reduction, $v_{b}(s)$, and to the next stop at a station, $v_{f b}(s)$, are calculated by using Equations (10) and (11).

$$
\begin{gathered}
v_{b}(s)=\sqrt{v_{\text {next }}^{2}+2 \cdot d_{\text {service }} \cdot\left(s_{\text {next }}-s\right),} \\
v_{f b}(s)=\sqrt{2 \cdot d_{\text {service }} \cdot\left(s_{\text {end }}-s\right),}
\end{gathered}
$$

where $v_{\text {next }}$ is the next ceiling speed of the track, $d_{\text {service }}$ is the service deceleration of the train, $s$ is the position of the train, $s_{n e x t}$ is the position of the next ceiling speed corrected with the train length if necessary and $s_{\text {end }}$ is the next stopping point.

The objective speed $v_{o b j}$ is therefore computed in terms of the maximum admissible speed $v_{\max }$, which is the minimum between the next braking curve and the ceiling speed at the position of the train $v_{\text {ceiling }}(s)$,

$$
\begin{gathered}
v_{\max }(t)=\min \left(v_{\text {ceiling }}(s), v_{b}(s), v_{f b}(s)\right), \\
v_{o b j}(t)=\min \left(v_{\max }(t), v_{c}\right) \quad \text { if } s \leq s_{c} \\
v_{o b j}(t)=0 \quad \text { if } s_{c}<s
\end{gathered}
$$

The control variable $U_{r e g}$ is defined as the traction or brake demand of the PI controller. To calculate it, at every time step the proportional and integral control components are calculated as described in Equations (14)-(18). For the standard driving the control variable is computed using Equation (17), while for the eco-driving strategy Equation (18) is used instead.

$$
\begin{gathered}
e(t)=v_{o b j}(t)-v(t) \\
U_{P}(t)=K_{P} \cdot e(t) \\
U_{I}(t)=\frac{K_{P}}{K_{I}} \cdot \frac{(e(t)+e(t-\Delta t))}{2}+U_{I}(t-\Delta t)
\end{gathered}
$$




$$
\begin{gathered}
U_{\text {reg }(s t d)}(t)=U_{P}(t)+U_{I}(t) \\
U_{\text {reg }(e c o)}(t)=U_{P}(t)+U_{I}(t) \quad \text { if } v(t) \geq v_{\max }(t) \text { or } U_{P}(t)+U_{I}(t) \geq 0 \\
U_{\text {reg }(e c o)}(t)=0 \quad \text { if } v(t)<v_{\max }(t) \text { and } U_{P}(t)+U_{I}(t)<0
\end{gathered}
$$

where $e(t)$ is the difference between the objective and the train speeds, whose absolute value has to be minimized by the control. $U_{P}(t)$ and $U_{I}(t)$ are the proportional and integral components of the control variable $U_{r e g}(t) . K_{P}$ and $K_{I}$ are the proportional and the integral gains, respectively. $\Delta t$ is the simulation time-step. If the control variable is positive, the control demands tractive effort, while if it is negative, it demands braking. If it is zero, the control demands coasting. In the eco-driving strategy (Equation (18)), the control demand is set to coasting when the train speed is below the maximum admissible speed and the control would demand braking under the current condition.

Once that the control variable has been obtained, the engine maximum traction and brake limits; comfort constraints-maximum acceleration and jerk; and the presence of neutral zones, have to be taken into account. Strong accelerations are considered to be unpleasant for passengers, so the maximum acceleration and deceleration have to be controlled. $F_{\max A c c}(\mathrm{~s}, v)$ and $F_{\max D e c}(\mathrm{~s}, v)$ model the forces corresponding to the maximum admissible acceleration and deceleration respectively with corrections for the running and track geometry resistances. Equations (19) and (20) are used for calculating these forces.

$$
\begin{aligned}
& F_{\text {maxAcc }}(\mathrm{s}, v)=a_{\text {max }} \cdot \rho \cdot m+\left(F_{r}(v)+F_{g}(s)\right) \\
& F_{\max D e c}(\mathrm{~s}, v)=d_{\max } \cdot \rho \cdot m+\left(F_{r}(v)+F_{g}(s)\right)
\end{aligned}
$$

where $a_{\max }$ and $d_{\max }$ are the maximum admissible acceleration and deceleration rates in absolute values, respectively.

The rate of change of the train acceleration, jerk, can also affect passengers' comfort [49,81-83]. The maximum and minimum admissible effort due to the jerk limitation, $F_{\text {maxjerk }}(\mathrm{t})$ and $F_{\text {minjerk }}(\mathrm{t})$, are calculated by using Equations (21) and (22).

$$
\begin{aligned}
& F_{\text {maxjerk }}(t)=F_{m}(t-\Delta t)-F_{b}(t-\Delta t)+\left(j_{\text {max }} \cdot \rho \cdot m\right) \cdot \Delta t \\
& F_{\text {minjerk }}(t)=F_{m}(t-\Delta t)-F_{b}(t-\Delta t)-\left(j_{\text {max }} \cdot \rho \cdot m\right) \cdot \Delta t
\end{aligned}
$$

where $j_{\max }$ is the maximum admissible jerk.

The total traction or braking effort demanded to the train after applying the comfort restrictions and engine maximum traction and brake effort, $F_{T B}(t)$, is computed by evaluating Equation (23) or Equation (24).

$$
\begin{gathered}
F_{T B}(t)=\min \left(U_{\text {reg }}(t), F_{\max }(v), F_{\text {max Acc }}(\mathrm{s}, v), F_{\text {maxjerk }}(t)\right) \\
\text { if } U_{\text {reg }}(t) \geq 0 \text { and } s \notin\left(s_{N Z_{\text {start }}^{k}}^{k} s_{N Z_{\text {end }}}^{k}\right) \text { for } k \in\{1,2, \ldots, z\}, \\
F_{T B}(t)=\max \left(U_{\text {reg }}(t), F_{\max D e c}(\mathrm{~s}, v), F_{\text {minJerk }}(t)\right) \\
\text { if } U_{\text {reg }}(t)<0 \text { and } s \notin\left(s_{N Z_{\text {start }}}^{k}, s_{N Z_{\text {end }}}^{k}\right) \text { for } k \in\{1,2, \ldots, z\} .
\end{gathered}
$$

If the train is on a neutral zone, it has to use the regenerative brake to maintain the comfort and auxiliary systems; therefore, the total braking effort to be applied is

$$
\begin{aligned}
F_{T B}(t)= & \max \left(\min \left(U_{\text {reg }}(t), F_{N Z}(v)\right), F_{\max D e c}(\mathrm{~s}, v), F_{\text {minjerk }}(t)\right) \\
& \text { if } s \in\left(s_{N Z_{\text {start }}}^{k}, s_{N Z_{\text {end }}}^{k}\right), \quad k \in\{1,2, \ldots, z\}
\end{aligned}
$$


where $F_{N Z}(v)$ is the minimum force required for keeping the auxiliary systems on; $s_{N Z} Z_{s t a r t}^{k}$ and $s_{N Z} Z_{\text {end }}^{k}$ are the initial and final points of the $k$-th neutral zone; and $z$ is the total number of neutral zones in the considered line.

Finally, the values of the tractive and brake forces to be applied in the train are obtained from the total traction or braking effort simply by considering that if $F_{T B}(t)$ is positive the train will apply traction and it will brake if $F_{T B}(t)$ is negative, as described in Equations (25) and (26).

$$
\begin{array}{cc}
F_{m}(t)=F_{T B}(t), & \text { if } F_{T B}(t) \geq 0, \\
F_{m}(t)=0 & \text { if } F_{T B}(t)<0, \\
F_{b}(t)=0 & \text { if } F_{T B}(t) \geq 0, \\
F_{b}(t)=-F_{T B}(t) & \text { if } F_{T B}(t)<0 .
\end{array}
$$

\section{Eco-Driving Optimization Algorithm}

A multi-agent based optimization method called MOPSO (multi-objective particle swarm optimization algorithm) [78] is used to generate energy-efficient speed profiles [44]. Energy consumption/running time Pareto fronts are obtained for different values of the engine traction and brake efficiencies and the linear resistance of the catenary.

This nature-inspired algorithm imitates the behavior of a swarm of insects looking for food. These insects are considered particles that move iteratively within a search space. In this case, each particle corresponds to a speed profile and the running time and energy consumption have to be optimized. A fitness value is assigned to each particle. In biology terms, fitness stands for a degree of adaptability of an insect or how close it is to an abundant source of food. To optimize its fitness, each particle position is updated at every iteration by computing its velocity as a function of its past position with best fitness, pbest, and the global best position found by the whole swarm, gbest. The latter variable accounts for the information shared between the particle ensemble.

To initialize the algorithm, a set of particles with random positions and velocities is generated. At every iteration $i$, the non-dominated solutions, which are those particles for which there are not any calculated solutions with lower running time and energy consumption, are stored in an archive $A$. The non-dominated solutions in $A$ are sorted in decreasing order by using a crowing distance $(C D)$ operator [44]. This way, the low-density zones of the Pareto front are given more priority. pbest of each particle is updated and gbest is drawn randomly from the archive, giving priority to the solutions with higher crowding distance, which correspond to the solutions at the top of $A$.

The positions and velocities of the particles at the next iteration are generated by using Equations (27) and (28),

$$
\begin{gathered}
v \hat{p}_{j}(i)=w v \hat{p}_{j}(i-1)+c_{1} r_{1}\left(\text { pbest }_{j}-\hat{x} \hat{p}_{j}(i-1)\right)+c_{2} r_{2}\left(g b e s t-\hat{x p} \hat{p}_{j}(i-1)\right) \\
x \hat{p}_{j}(i)=\hat{x} \hat{p}_{j}(i-1)+v \hat{p}_{j}(i)
\end{gathered}
$$

where $x \hat{p}_{j}, v \hat{p}_{j}$ are the position and velocity of the $j$-th particle; $w$ is an inertia constant that weights the previous velocities; $c_{1}$ and $c_{2}$ are two social factor constants that weight the distance to pbest ${ }_{j}$; and gbest, $r_{1}$ and $r_{2}$ are random numbers drawn uniformly between 0 and 1 .

After the position of all the particles in the current iteration has been updated, the new non-dominated solutions are included in the archive and all the newly dominated solutions are deleted. pbest is updated for all the solutions in the archive. The solutions in $A$ are sorted in decreasing order of $C D$, and finally, the gbest is drawn randomly from $A$, giving a higher probability to those solutions with higher $C D$. This procedure is repeated until a certain number of iterations I is reached. Figure 1 shows the MOPSO algorithm flowchart. 


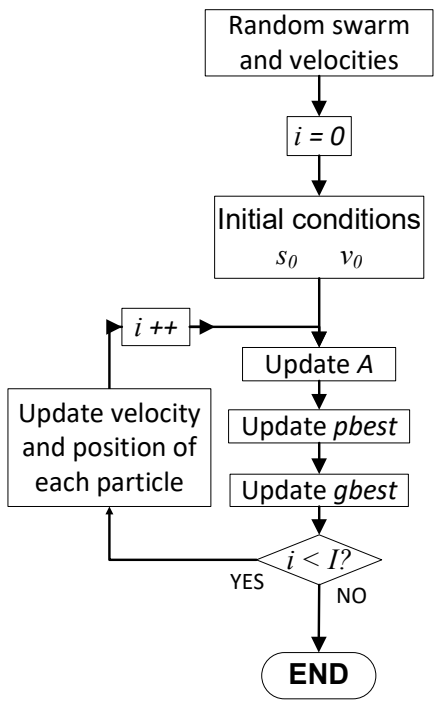

Figure 1. MOPSO algorithm flowchart.

\section{Case Study and Results}

In this section, the holding speed without braking with final coasting eco-driving strategy is compared against the standard holding speed driving, and the difference in energy consumption is quantified. In both cases, there is a single cruise speed and all the energy regenerated by the electrical brake is assumed to be returned to the power grid. The dependence of the energy consumption (measured at pantograph and at substations) on the engine efficiency and catenary linear resistance is analyzed. The nature-inspired optimization algorithm introduced in Section 5 is used for obtaining the Pareto front of speed profiles for the Talgo-Bombardier class 102 train running on two sections of Spanish high-speed lines. Track grades, curves, speed limits, tunnels, neutral zones and the positions of electrical substations are considered in the line models.

The first section analyzed is an $85.4 \mathrm{~km}$ long section between Calatayud and Zaragoza in the Madrid-Barcelona line with a $2 \times 25 \mathrm{kV}$ power supply system. The second section is a $38.9 \mathrm{~km}$ long line section between Puertollano and Ciudad Real in the Madrid-Sevilla line, with a $1 \times 25 \mathrm{kV}$ power supply system. The train has two $8 \mathrm{MW}$ engines of $200 \mathrm{kN}$ of maximum traction effort. The maximum traction curve is shown in Figure 2. The power consumed by the auxiliary systems is $325 \mathrm{~kW}$ and in any neutral zone the train has to regenerate enough energy to maintain these systems on, as presented in Equation (24). The running resistance curve is presented in Figure 3. The empty mass of the train is $324 \mathrm{t}$, and its length is $200 \mathrm{~m}$. Furthermore, apart from the train's empty mass, $50 \mathrm{t}$-worth of passengers have been taken into account.

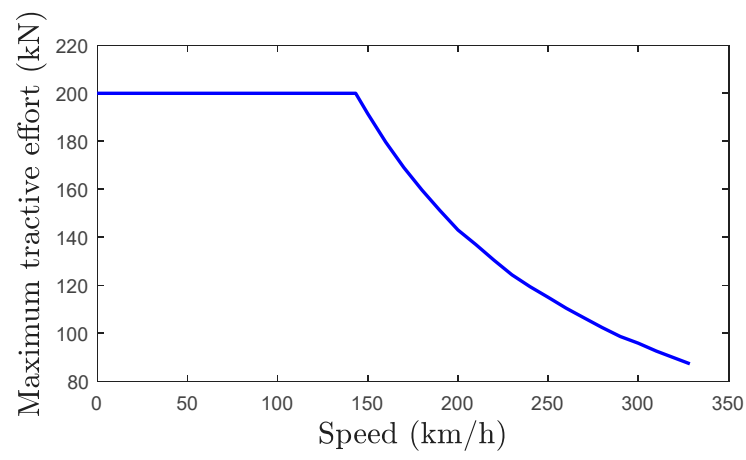

Figure 2. Maximum tractive effort curve for the considered Talgo-Bombardier class 102 train. 


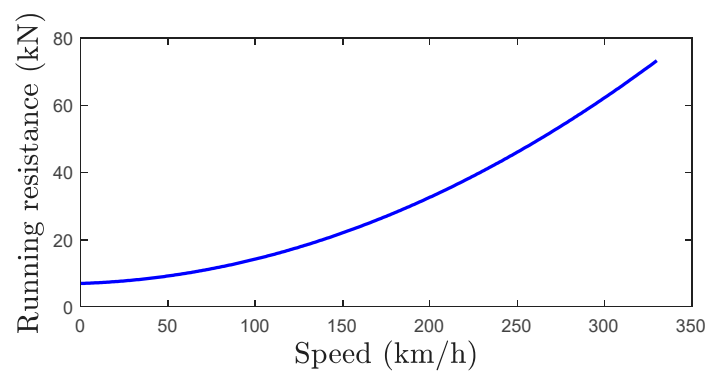

Figure 3. Running resistance for the Talgo-Bombardier class 102 train. It is modelled by using Equation (6).

Regarding the comfort constraints, the maximum and the service decelerations are $0.4 \mathrm{~m} / \mathrm{s}^{2}$, the maximum acceleration is $0.67 \mathrm{~m} / \mathrm{s}^{2}$ and the maximum admissible jerk is, in absolute value, $0.7 \mathrm{~m} / \mathrm{s}^{3}$. The power constant is considered to be $\cos \varphi=1$. The social factors $c_{1}$ and $c_{2}$ in the MOPSO algorithm are equal to 2 and the inertia constant $w$ is 0.2 .

\subsection{Calatayud-Zaragoza Case Study}

Figure 4 shows the height profile of the line section between Calatayud and Zaragoza. As can be seen, the considered section is mostly downhill. There are three neutral zones, which are represented in magenta in the lower part of the figure.

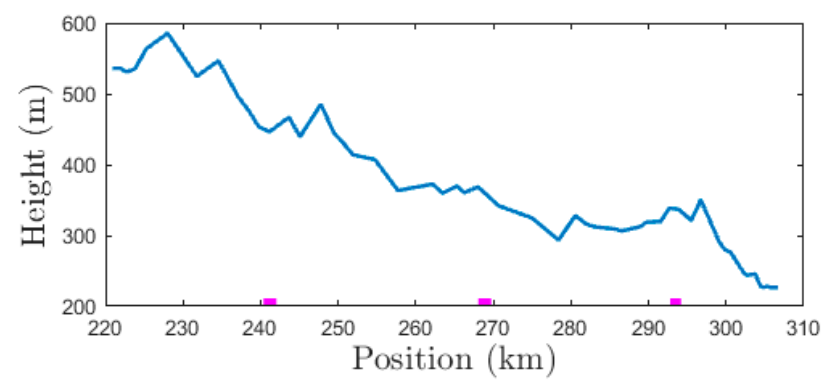

Figure 4. Height profile of the Calatayud-Zaragoza section. Neutral zones are represented in magenta.

In this subsection, the impact of the efficiency ratio of the motors on the energy consumption is analyzed for both driving strategies. The traction and brake engine efficiencies are considered equal and constant within a range between $85 \%$ and $97 \%$. The influence of the linear resistance of the catenary on the energy consumption is also studied. In the case of the Calatayud-Zaragoza section, the catenary configuration is $2 \times 25 \mathrm{kV}$, and different values of its linear resistance, between $21 \cdot 10^{-6} \Omega / \mathrm{m}$ and $37 \cdot 10^{-6} \Omega / \mathrm{m}$, are tested. The MOPSO algorithm was used to generate speed profiles for both standard and eco-driving strategies. For each driving strategy the non-dominated speed profiles in terms of energy consumption and running time define the Pareto front. Figure 4 shows Pareto fronts for the net consumption measured at the electrical substations for the extreme values of the considered interval for the efficiency ratio of the motors and for the linear resistance of the catenary. The Pareto fronts corresponding to the eco-driving strategy are represented in blue, while those corresponding to the standard driving strategy are represented in red.

As shown in Figure 5, the consumed energy decreases as the engine efficiency increases. The energy consumption increases for higher values of the linear resistance, since more regenerated energy is dissipated at the catenary. For the fastest speed profilesm the difference in energy consumption is significantly lower than for the rest. These speed profiles are close to the flat-out speed profile; thus, the final coasting phase is very short, and therefore has little relevance in terms of energy-saving, so both driving strategies produce similar results in terms of energy consumption. It can also be observed that the eco-driving strategy produces faster and less energy-consuming speed profiles than 
the standard driving strategy, as all the solutions for the latter one are dominated by those produced by the former. Table 1 is focused on the analysis for the commercial running time ( $24 \mathrm{~min}$ ), varying the efficiency ratio and the linear resistance. It shows the difference (in \%) in net energy consumption at the electrical substations between both driving strategies. Results shown in this table are especially relevant for the infrastructure administrator.
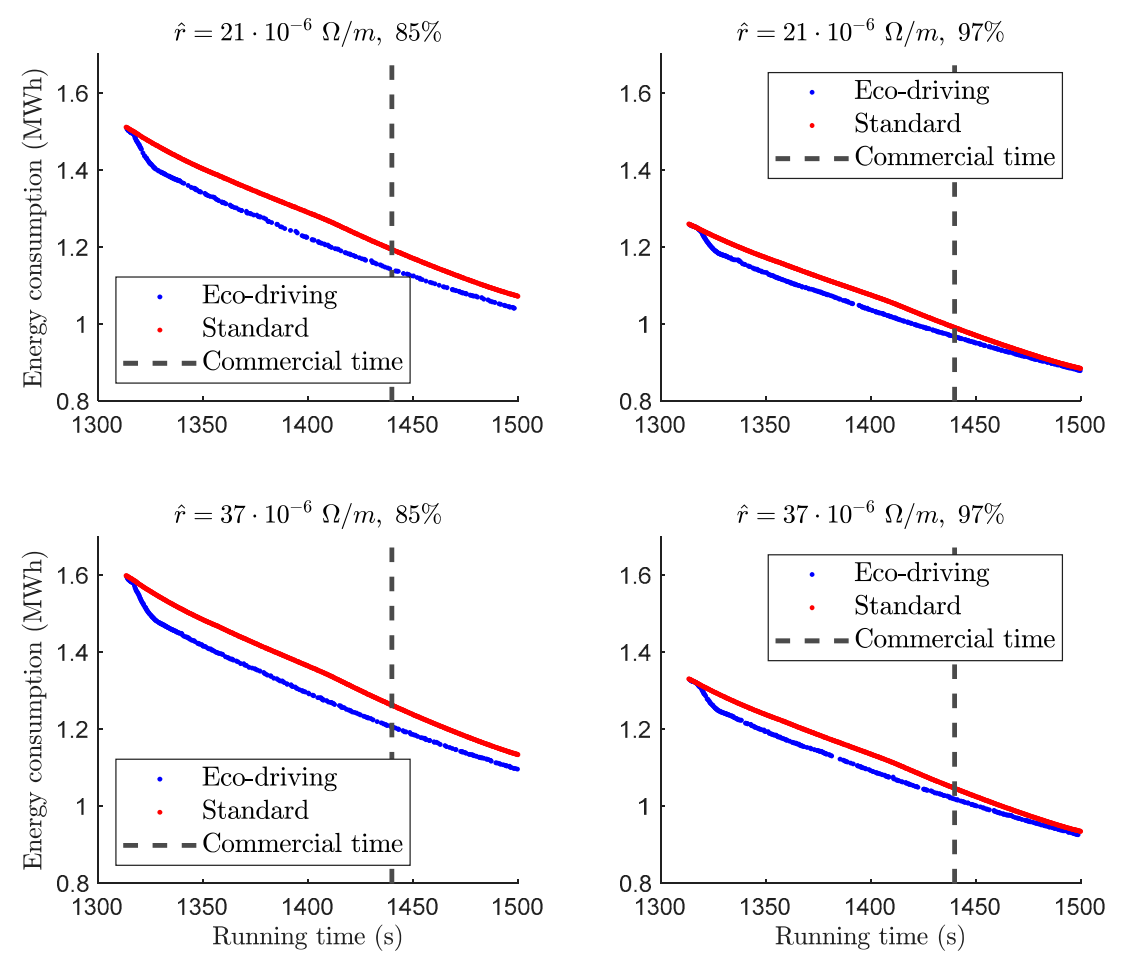

Figure 5. Pareto fronts for the net consumption at the electrical substations for the considered extreme values of the engine traction and braking efficiency $(85 \%$ and $97 \%)$ and linear resistance of the catenary $\left(21 \cdot 10^{-6} \Omega / \mathrm{m}\right.$ and $\left.37 \cdot 10^{-6} \Omega / \mathrm{m}\right)$, for the Calatayud-Zaragoza section.

Table 1. Difference (in \%) in net energy consumption at the electrical substations between the eco-driving and standard driving strategies for different values of the energy traction and braking efficiency and the linear resistance in the Calatayud-Zaragoza section for the commercial running time (24 min).

\begin{tabular}{|c|c|c|c|c|c|c|}
\hline & & \multicolumn{5}{|c|}{ Engine Traction and Braking Efficiency (\%) } \\
\hline & & 85.00 & 88.00 & 91.00 & 94.00 & 97.00 \\
\hline \multirow{5}{*}{$\begin{array}{l}\text { Linear resistance of the catenary } \\
\qquad\left(\times 10^{-6} \Omega / \mathrm{m}\right)\end{array}$} & 21 & $4.54 \%$ & $3.89 \%$ & $3.56 \%$ & $2.99 \%$ & $2.48 \%$ \\
\hline & 24 & $4.56 \%$ & $4.08 \%$ & $3.58 \%$ & $3.10 \%$ & $2.51 \%$ \\
\hline & 28 & $4.59 \%$ & $4.13 \%$ & $3.62 \%$ & $3.12 \%$ & $2.54 \%$ \\
\hline & 32 & $4.63 \%$ & $4.17 \%$ & $3.68 \%$ & $3.17 \%$ & $2.64 \%$ \\
\hline & 37 & $4.69 \%$ & $4.23 \%$ & $3.78 \%$ & $3.30 \%$ & $2.76 \%$ \\
\hline
\end{tabular}

In Table 1, two trends can be observed. The difference in energy consumption decreases as the linear resistance of the catenary decreases. It decreases even more significantly when the efficiencies of the engine brake and traction are higher. The energy saving at the electrical substations between the eco-driving strategy and the standard driving is $2.47-4.69 \%$.

Obviously, the measured energy consumption at the pantograph does not depend on the linear resistance of the catenary. Figure 6 shows the dependence of the energy savings (measured at the pantograph) on the energy efficiency. 


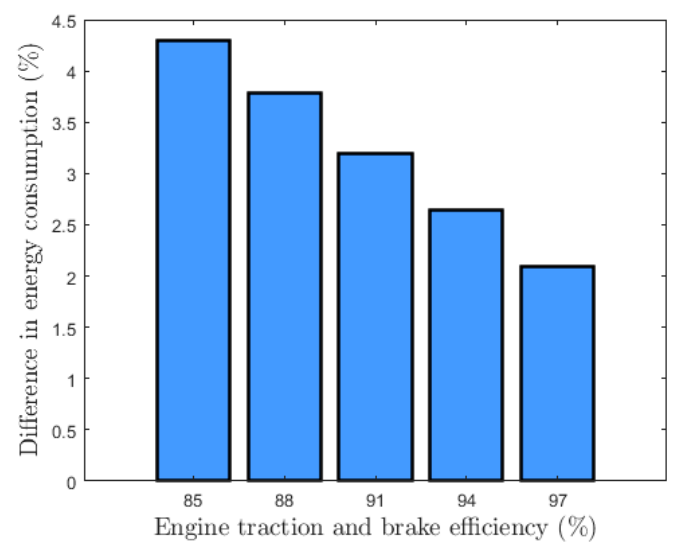

Figure 6. Difference in energy consumption at the pantograph (in \%) between the considered driving strategies for different values of the engine traction and brake efficiency in Calatayud-Zaragoza section.

It may be observed that for the considered engine efficiency interval, there is an approximately linear relation between the difference in energy consumption and the engine efficiency. The eco-driving strategy produces speed profiles with lower energy consumption than the standard driving strategy. Results shown in Figure 6 are especially relevant for train operators. The energy saving measured at pantograph of eco-driving with respect to standard driving is between $2.1 \%$ and $4.3 \%$.

In Figure 7 the difference in energy consumption at the substations is analyzed for each linear resistance of catenary. Results are shown for different values of the engine efficiency and running time. A grey vertical dashed line is used to highlight the commercial running time, which is $24 \mathrm{~min}$.
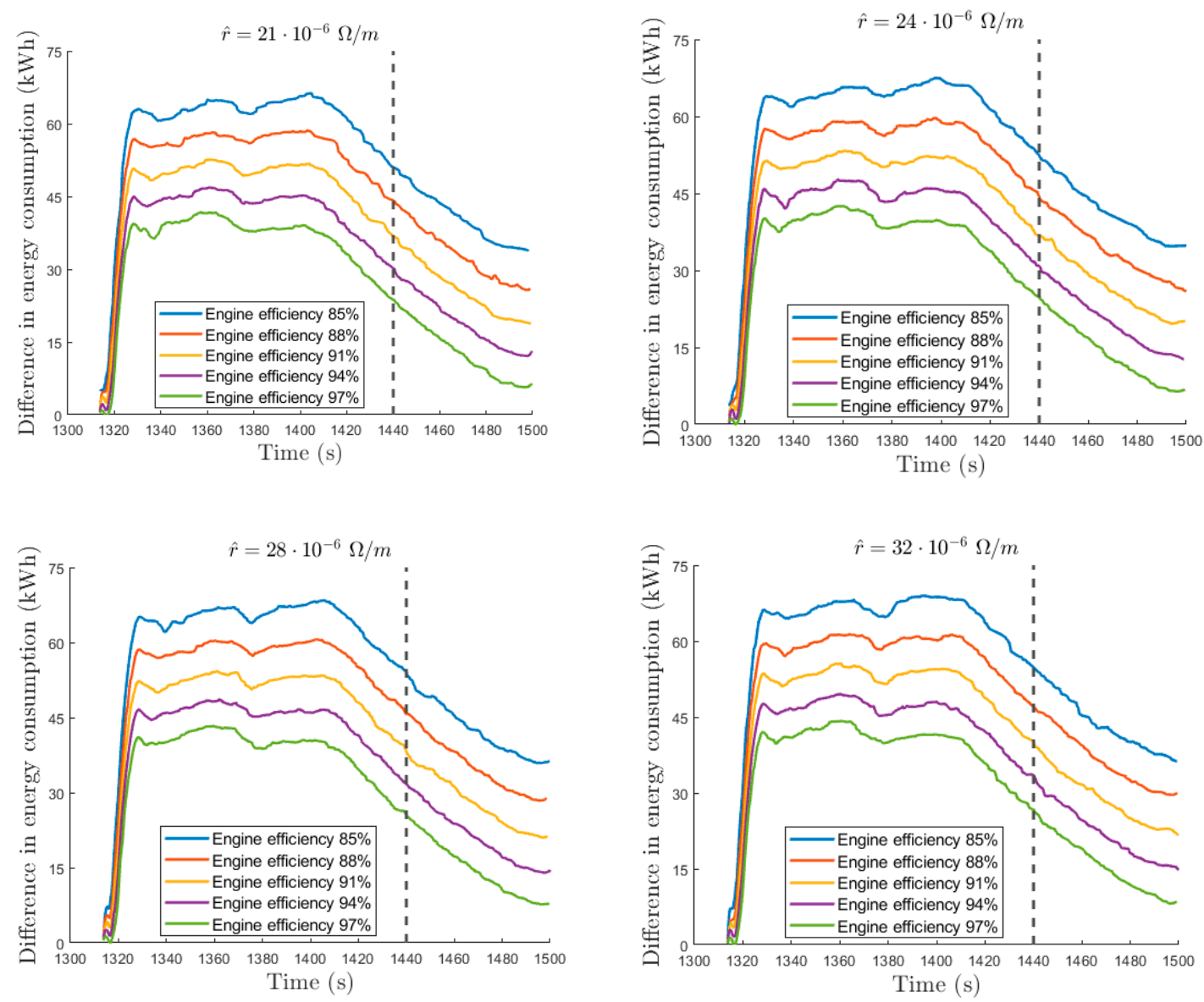

Figure 7. Cont. 


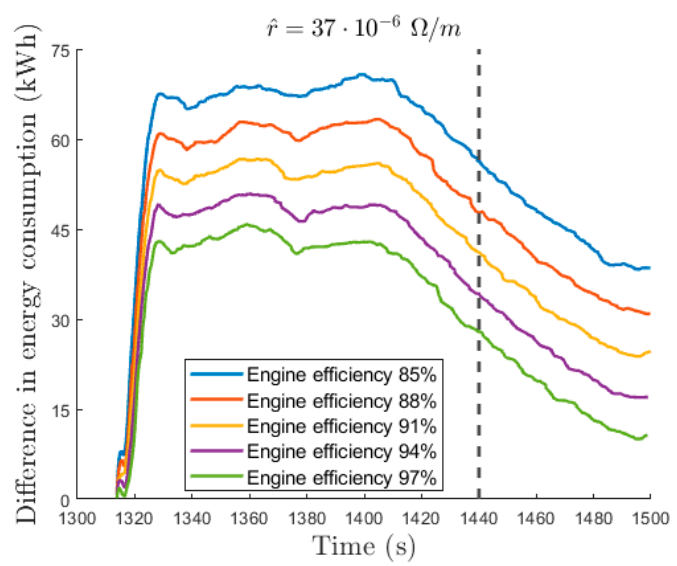

Figure 7. Difference in energy consumption (in $\mathrm{kWh}$ ) between the considered driving strategies at the electrical substations for the Calatayud-Zaragoza section for different values of the catenary linear resistance $\hat{r}$.

Three different scenarios can be distinguished. Close to the flat-out running time, there is a large increase in the difference in energy consumption between the eco-driving and the standard driving strategies; this is due to the action of the final coasting phase in the former driving strategy. Next, there is a scenario in which the difference is approximately constant. For the slowest speed profiles, the difference in energy consumption is significantly lower, as can be seen in Figure 5, and the difference in energy consumption between the considered driving strategies becomes smaller as the running time increases, as the coasting phase will be shorter and therefore its impact will be less significant. If the dependence of the results on the energy braking and traction efficiency is considered, it can be observed that for a fixed running time the difference in energy consumption seems to depend linearly on the difference in energy efficiency. For the same value of the engine efficiency, the difference in energy consumption increases slightly with the linear resistivity of the catenary.

Last, the speed profiles obtained for the commercial time with the two considered driving strategies are presented. Table 2 shows the command vectors for these two speed profiles. Notice that the considered line section ends at kilometric point (k.p.) 306.7 at Zaragoza station (stopping point). The coasting phase in eco-driving starts $18 \mathrm{~km}$ before the stopping point.

Table 2. Command vectors for the commercial time speed profiles obtained with the two considered driving strategies for Calatayud-Zaragoza section.

\begin{tabular}{ccc}
\hline & Eco-Driving Strategy & Standard Driving Strategy \\
\hline Cruise speed $(\mathrm{km} / \mathrm{h})$ & 253.0 & 249.2 \\
Final position of the cruise phase $(\mathrm{km})$ & 288.7 & Braking curve \\
\hline
\end{tabular}

In Figures 8 and 9, the speed profiles are shown. The train speed is represented in blue, the speed limits are represented by red lines and the track altitude is shown in green. The holding speed is represented by an orange dashed line. 


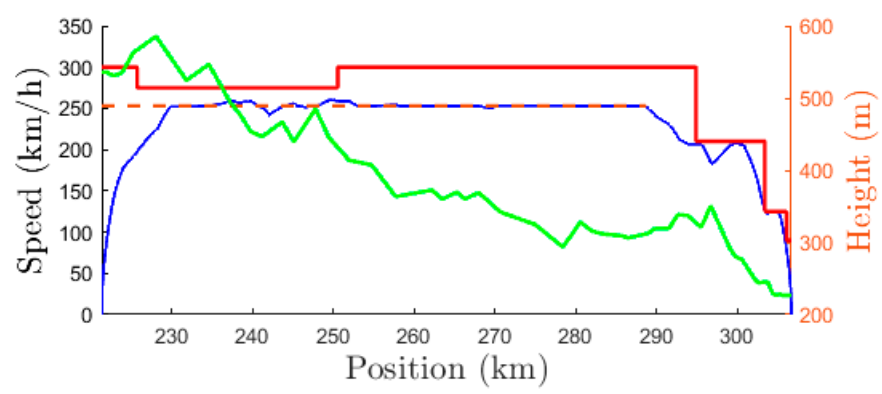

Figure 8. Eco-driving speed profile for the commercial time in the Calatayud-Zaragoza section.

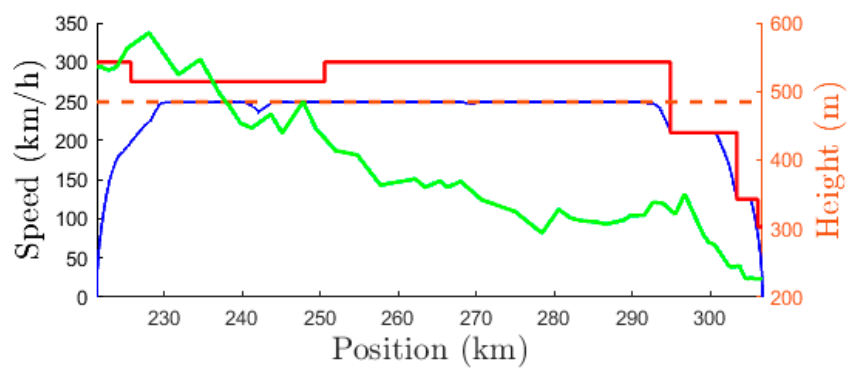

Figure 9. Standard driving speed profile for the commercial time in the Calatayud-Zaragoza section.

Figure 8 shows that in the holding speed regimes there are few points in which the train goes faster than the cruise speed in the eco-driving strategy, as there are few steep downhill grades. The most significant difference between the two speed profiles in Figures 8 and 9 is after position $288.7 \mathrm{~km}$, in which the train is coasting in Figure 8, while in Figure 9 it is holding its speed until it reaches the braking curve. Near position $300 \mathrm{~km}$ the train has to brake due to the presence of a speed limit.

\subsection{Puertollano-Ciudad Real Case Study}

Finally, results are shown for the second case study, in which eco-driving speed profiles were designed for the considered Talgo-Bombardier class 102 train in a $38.9 \mathrm{~km}$ long line section between Puertollano and Ciudad Real. This line section has a catenary configuration of $1 \times 25 \mathrm{kV}$, and three different values of its linear resistance between $54 \cdot 10^{-6} \Omega / \mathrm{m}$ and $110 \cdot 10^{-6} \Omega / \mathrm{m}$ are considered in this study. In Figure 10 the height profile of the considered line section is represented in blue, while the two neutral zones are represented in magenta in the lower part of the figure. In general terms, this line section is flatter than the Calatayud-Zaragoza line section.

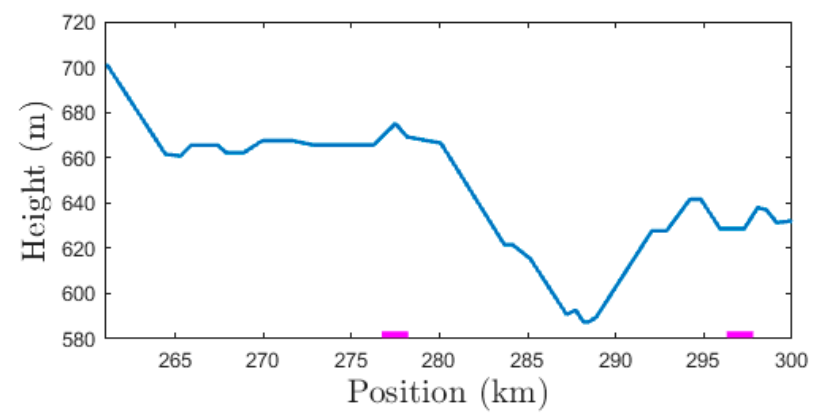

Figure 10. Height profile of the line section between Puertollano and Ciudad Real. Neutral zones are represented in magenta.

Again, speed profiles were generated for the two considered driving strategies by using the MOPSO algorithm. The obtained Pareto fronts are represented in Figure 11, in which they are sorted in terms of the net consumption at the substations. Results are shown for the extreme values of the 
considered engine efficiency interval, $85 \%$ and $97 \%$ and for catenary linear resistances $54 \cdot 10^{-6} \Omega / \mathrm{m}$, $70 \cdot 10^{-6} \Omega / \mathrm{m}$ and $110 \cdot 10^{-6} \Omega / \mathrm{m}$. The standard and eco-driving speed profiles are represented in red and blue, respectively. The commercial time, which is $13 \mathrm{~min}$, is highlighted by a vertical grey dashed line.
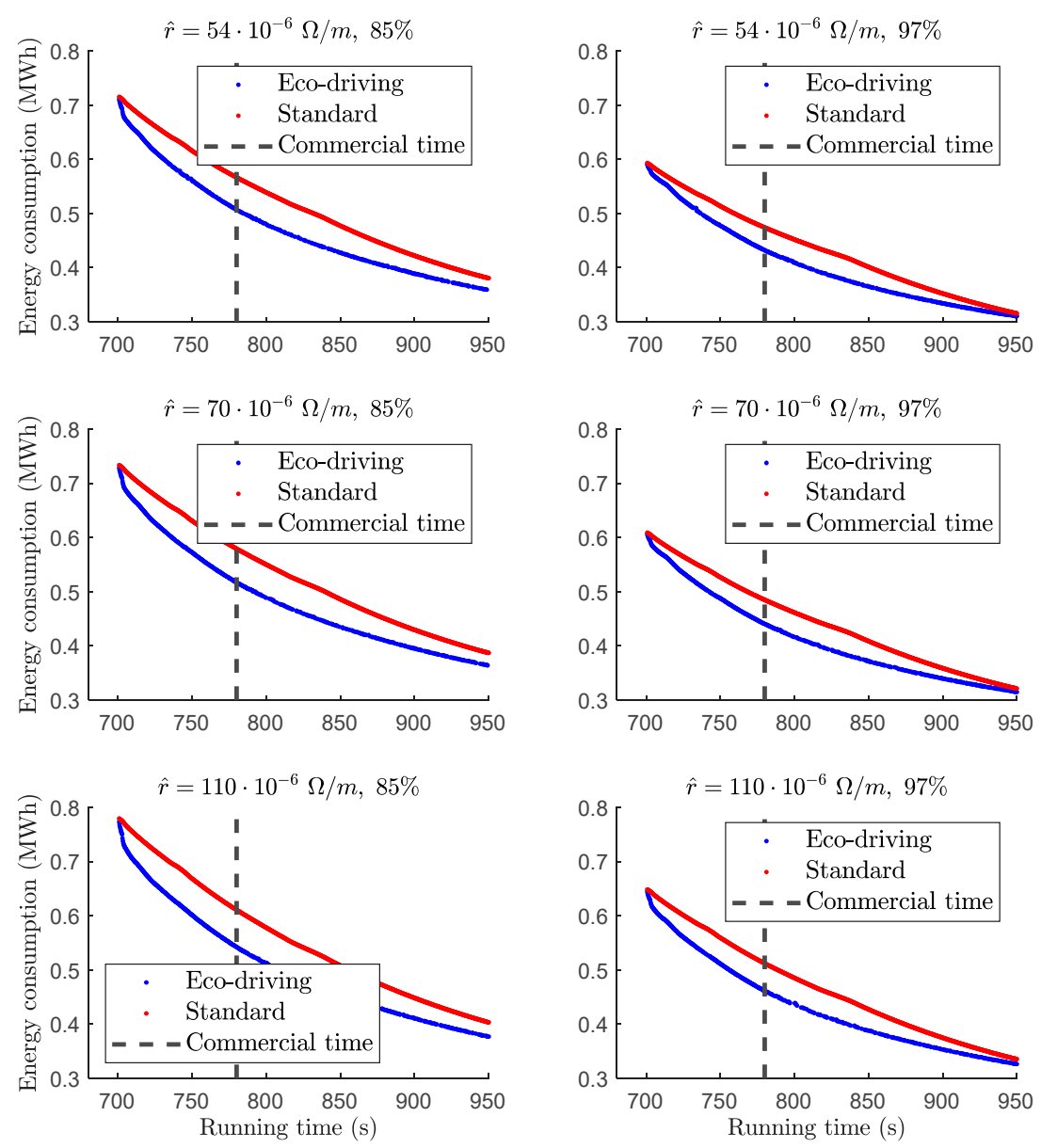

Figure 11. Pareto fronts for the net consumption at the electrical substations for the extreme values of the engine traction and braking efficiency ( $85 \%$ and $97 \%$ ) and the three considered values of the linear resistance of the catenary $\left(54 \cdot 10^{-6} \Omega / \mathrm{m}, 70 \cdot 10^{-6} \Omega / \mathrm{m}\right.$ and $\left.110 \cdot 10^{-6} \Omega / \mathrm{m}\right)$.

Results presented in Figure 11 are similar to those in Figure 5, although this time the difference in energy consumption between two solutions with the same running time is usually larger than in the Calatayud-Zaragoza case. For a fixed running time, the energy consumption is larger when the engine is more inefficient and when the catenary has a larger linear resistance. The speed profiles in the holding speed without a braking Pareto curve dominate those in the holding speed with a braking Pareto curve.

Table 3 shows the difference in energy consumption at the substations between the two considered driving strategies for the commercial running time in the Puertollano-Ciudad Real section. Results are shown for different values of the engine efficiency and the linear resistance of the catenary. 
Table 3. Difference (in \%) in energy consumption at the electrical substations between the holding speed with braking and the holding speed without braking and final coasting driving strategies for different values of the energy traction and braking efficiency and the linear resistance in the Puertollano-Ciudad Real section for the commercial running time (13 $\mathrm{min})$.

\begin{tabular}{ccccccc}
\hline & \multicolumn{5}{c}{ Engine Traction and Braking Efficiency (\%) } \\
\cline { 3 - 6 } & & $\mathbf{8 5 . 0 0}$ & $\mathbf{8 8 . 0 0}$ & $\mathbf{9 1 . 0 0}$ & $\mathbf{9 4 . 0 0}$ & $\mathbf{9 7 . 0 0}$ \\
\hline \multirow{2}{*}{$\begin{array}{c}\text { Linear resistance of the catenary } \\
\left(\times 10^{-6} \Omega / \mathrm{m}\right)\end{array}$} & 54 & $11.86 \%$ & $11.33 \%$ & $10.81 \%$ & $10.28 \%$ & $9.70 \%$ \\
& 110 & $12.07 \%$ & $11.62 \%$ & $11.12 \%$ & $10.40 \%$ & $10.15 \%$ \\
\hline
\end{tabular}

Once again, the lower the linear resistance is, the lower the difference in energy consumption is. Moreover, the difference in consumption between two speed profiles produced by using the two considered strategies is higher when the train engine is less efficient. The difference in energy consumption between the considered driving strategies for the commercial running time is between $9.70 \%$ and $12.55 \%$.

Figure 12 shows the energy consumption measured at the pantograph for the commercial time speed profiles. As can be observed, for an engine efficiency of $85 \%$, the eco-driving strategy can be used for achieving a 10.8\% energy saving with respect to the standard driving strategy, while for an engine efficiency of $97 \%$ the energy saving between the two strategies is $8.3 \%$.

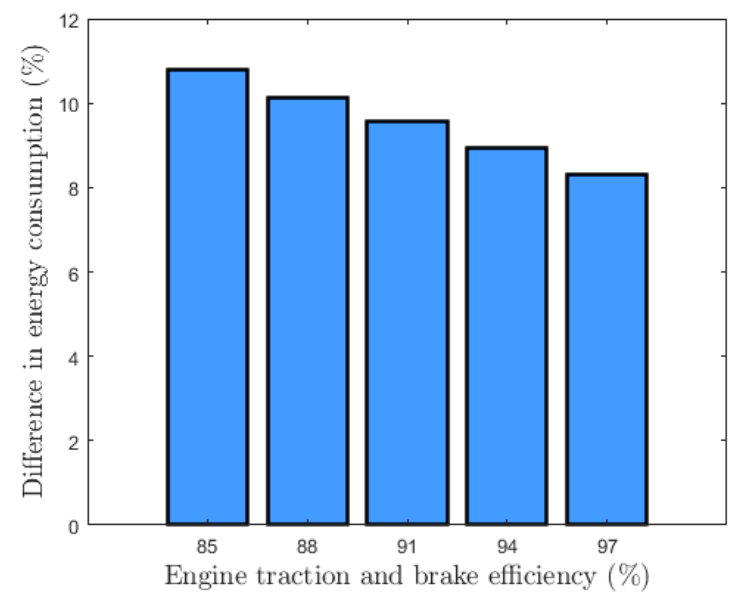

Figure 12. Difference in energy consumption at the pantograph (in \%) between the considered driving strategies for different values of the engine traction and brake efficiency in Puertollano-Ciudad Real section.

The difference in energy consumption between the considered driving strategies is analyzed in Figure 13 for the considered linear resistances of the catenary and engine efficiencies and for different running times.

The difference in energy consumption grows up to a maximum close to the commercial running time. The commercial running time ( $13 \mathrm{~min}$, that is $780 \mathrm{~s}$ ) is highlighted by means of a grey dashed line. The more-or-less constant scenario in Figure 7 is at this point concave; this indicates that the shape of the difference in energy consumption depends on the height profile of the track. This time, the difference in energy consumption is larger when considering different values of the linear resistivity, as there is a larger difference between those values. Again, the difference in consumption seems to decrease linearly with the engine efficiency. 

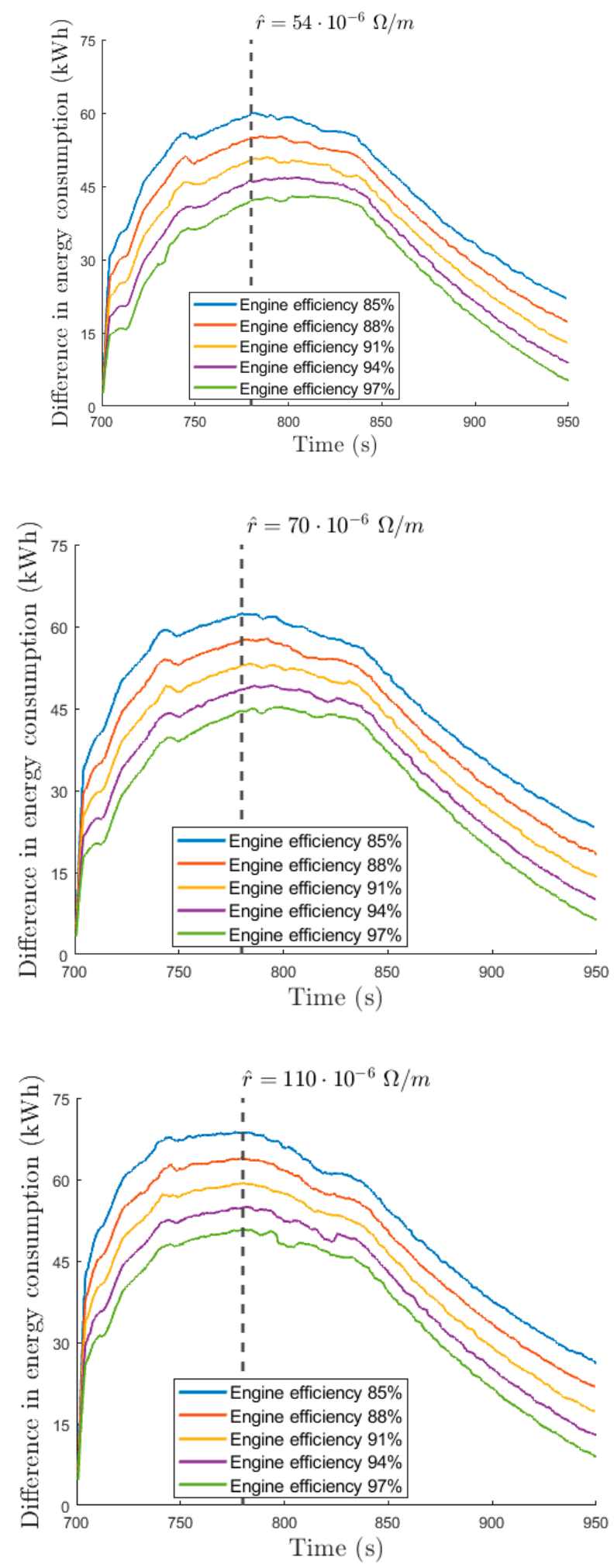

Figure 13. Difference in energy consumption (in $\mathrm{kWh}$ ) between the considered driving strategies at the electrical substations for the Puertollano-Ciudad Real section for different running times. Different values of the catenary linear resistance $\hat{r}$ and different values of the engine efficiency are considered.

In Table 4 the command vectors of the two driving speed profiles that satisfy the commercial running time are presented. The eco-driving final coasting phase is approximately $10 \mathrm{~km}$ long and its cruise speed is $17.4 \mathrm{~km} / \mathrm{h}$ higher. Figures 14 and 15 show the commercial speed profiles obtained for 
the eco-driving and standard driving strategies, respectively. The train speed is represented in blue, the speed limits are represented by red lines and the track altitude is shown in green. The holding speed is represented by an orange dashed line.

Table 4. Command vectors for the commercial time speed profiles obtained with the two considered driving strategies for the Puertollano-Ciudad Real section.

\begin{tabular}{ccc}
\hline & Eco-Driving Strategy & Standard Driving Strategy \\
\hline Cruise speed $(\mathrm{km} / \mathrm{h})$ & 236.5 & 219.1 \\
Final position of the cruise phase $(\mathrm{km})$ & 287.1 & Braking curve \\
\hline
\end{tabular}

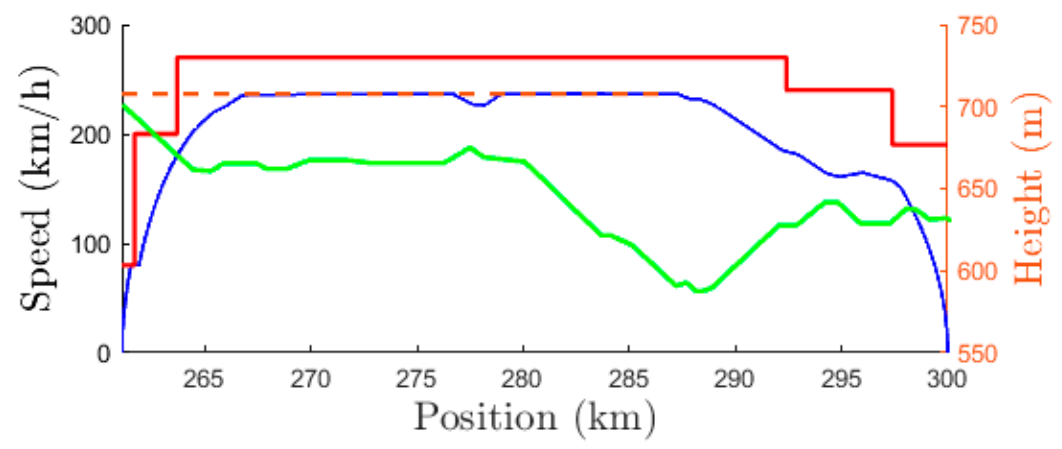

Figure 14. Eco-driving speed profile for the commercial time in the Puertollano-Ciudad Real line section.

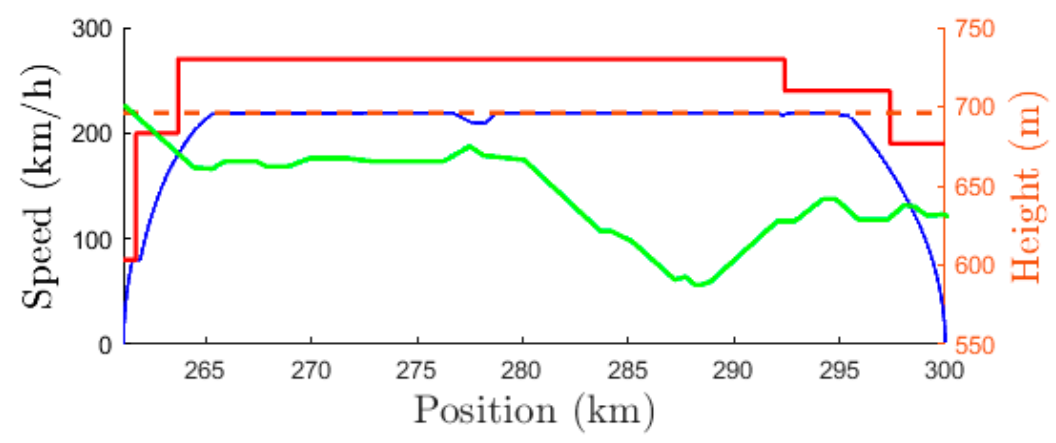

Figure 15. Standard driving speed profile for the commercial time in the Puertollano-Ciudad Real line section.

In this case, the train coasts approximately in $25 \%$ of the total length of the line section. In comparison to Figures 8 and 9 , in this section the role of the final coasting phase is more important. This explains the fact that the difference in energy consumption between the considered driving strategies in percentage is much higher for the Puertollano-Ciudad Real section.

\section{Discussion}

The studies developed in this paper have been carried out with the objective of assessing the effectiveness of eco-driving under different electrical scenarios and to answer the question about whether or not eco-driving is useful in high-receptivity networks. The results obtained suggest that the answer to the question is that it is useful to apply eco-driving. Besides, it has to be taken into account that the value of energy saving because of efficient driving will depend on the efficiency of the electrical chain (catenary loses and motor efficiency) and on the running time.

The cases studied in Section 6 are two cases of an alternate current power supply system with high receptivity. These systems are, by nature, much more effective using regenerate energy than direct current systems. In alternate current systems, the energy generated by train braking can be used by other trains or sent back to the distribution network for other uses. However, there is part of the 
regenerated energy that will be lost anyway because of the catenary losses and the motor's efficiency. Saving part of the lost energy is the main benefit of eco-driving, and the results support this. It has been shown that, the lower the energy lost in the motor and catenary, the lower the difference between efficient non-efficient driving.

The results obtained in Puertollano-Ciudad Real show energy savings produced by eco-driving according to the typical values between $10 \%$ and $15 \%$ in the literature [68]. On the other hand, the results obtained in Calatayud-Zaragoza present values that are further reduced. One reason to explain this is the track profile. Although the average grade in both cases is downhill, the difference in altitude between the end and start of the journey is higher in Calatayud-Zaragoza. The presence of steeper downhills leads to lower energy consumption results and lower differences between different speed profiles.

Catenary losses can also explain why the energy reduction figures obtained by the eco-driving strategy in the Calatayud-Zaragoza stretch are lower than those obtained in the Puertollano-Ciudad Real stretch (the $2 \times 25 \mathrm{kV}$ system is more efficient than the $1 \times 25 \mathrm{kV}$ system because of lower rate of power losses).

The influence of the commercial running time cannot be neglected. In both cases, it can be observed that there are three scenarios of energy saving due to eco-driving depending on the running time. Close to the flat-out running time, the energy saving that can be obtained by efficient driving is zero because there is no possibility of modifying the driving to obtain the minimum running time. From there, there is a small interval of running time wherein the energy saving provided by eco-driving increases as the running time increases. After that, there is a zone of running time values in which the energy saving rate is approximately constant. This zone typically contains the commercial running time for the journey. Finally, for the largest running times, the difference in energy consumption between efficient and non-efficient driving is gradually reduced.

Therefore, a second order reason for the reduced energy saving figures in Calatayud-Zaragoza is that the commercial running time of this journey is higher than usual and it is located in the running time interval in which the energy savings provided by eco-driving are reduced.

Despite this, the minimum energy saving provided by eco-driving is relevant $(2.5 \%)$ in a scenario of $97 \%$ motor efficiency. This motor efficiency is very high compared with its typical values, which are between $85 \%$ and $90 \%$. Therefore, taking into account the typical motor efficiency, the minimum energy saving provided by eco-driving can reach more that $3.5 \%$.

With these results, it can be said that high network receptivity to braking energy can mitigate the effect of eco-driving, but it is still significant.

Obviously, results can vary in a field-test because of simulation error. However, as explained in Section 2, the value of simulation error in energy consumption is $0.4 \%$. This error can slightly quantitatively modify the results obtained but cannot qualitatively modify them and the trends obtained.

\section{Conclusions}

The basis of eco-driving strategy is the substitution of the use of braking with coasting periods. Trains equipped with regenerative braking allow for recovering the kinetic energy during deceleration phases, which can be used by other trains or sent back to the utility grid in AC power supply systems or in DC systems equipped with reversible substations. In this context of high use of regenerated energy, it is necessary to analyze whether eco-driving design based on coast commands has an impact on energy savings. In this work, an eco-driving strategy has been compared to a standard driving strategy. The former one consists on holding a cruise speed without braking (if braking is needed to maintain that speed, it is not applied and the speed increases) and coasting before braking. The latter one consists of holding the cruise speed and braking if it is necessary to do so. A comparison has been performed in two real case studies by simulating a train on two high-speed Spanish lines. One of them is a section of the Madrid-Barcelona high-speed line, which is fed by a $2 \times 25 \mathrm{kV}$ power supply system. The other one is a section of the Madrid-Sevilla high-speed line, which is fed by a $1 \times 25 \mathrm{kV}$ 
power supply system. The influence of the regenerated energy losses at the catenary-which depend on its linear resistance, and the engine traction and braking efficiency, which are considered constant and equal-on the energy consumption of the speed profiles generated for both driving strategies has been studied. To generate the driving commands, a nature-inspired algorithm called MOPSO has been used for both driving strategies. Speed profiles have been obtained by simulating driving commands. For each driving strategy and for some values of the linear resistance and engine efficiency, the Pareto curves consisting of the non-dominated speed profiles in terms of energy consumption and running time have been computed. The difference in energy consumption between the considered driving strategies has been calculated for different values of the catenary resistance, engine efficiency and running time, with a special focus on the commercial time. For the commercial running time, the eco-driving strategy produces energy savings with respect to the standard driving strategy between $2.48 \%$ and $4.69 \%$ at the pantograph for the first case study and between $9.7 \%$ and $12.55 \%$ for the second.

For a specific running time, the holding speed without braking and final coasting eco-driving strategy produces solutions that consume less energy than the holding speed with braking standard driving strategy. The difference in energy consumption between the considered driving strategies is larger when the losses at the catenary are more significant and when the engine is less efficient.

It was found that the holding speed without braking and final coasting driving strategy produces speed profiles more energy-efficient than the standard driving strategy, mostly due to the final coast phase. For slower speed profiles, the energy consumption is much lower, as the cruise speed is lower; the final coast phase takes place more close to the brake curve at the end of the section; and then the difference in energy consumption between the considered driving strategies is smaller.

Finally, it can be concluded that, although the power supply network presents a high receptivity to braking energy, the eco-driving design can produce significant energy savings.

Author Contributions: A.C.: investigation, writing-original draft preparation. A.F.-R.: investigation, software, writing-original draft preparation. A.P.C.: conceptualization, methodology, investigation, writing-review and editing. A.F.-C.: conceptualization, methodology, investigation, writing-review and editing. M.C.F.: writing-review and editing. All authors have read and agreed to the published version of the manuscript.

Funding: This research received no external funding.

Conflicts of Interest: The authors declare no conflict of interest.

\section{References}

1. IEA. Energy Consumption and $\mathrm{CO}_{2}$ Emissions. In UIC Railway Handbook 2017; IEA: Paris, France, 2017.

2. UNIFE/Roland Berger World Rail Market Study: Forecast 2016 to 2021; UNIFE: Brussels, Belgium, 2016.

3. Bae, C.H. A simulation study of installation locations and capacity of regenerative absorption inverters in DC 1500 V electric railways system. Simul. Model. Pract. Theory 2009, 17, 829-838. [CrossRef]

4. Barrero, R.; Mierlo, J.V.; Tackoen, X. Energy savings in public transport. IEEE Veh. Technol. Mag. 2008, 3, $26-36$. [CrossRef]

5. Cornic, D. Efficient recovery of braking energy through a reversible dc substation. In Proceedings of the Electrical Systems for Aircraft, Railway and Ship Propulsion, Bologna, Italy, 19-21 October 2010; pp. 1-9.

6. López-López, Á.J.; Pecharromán, R.R.; Fernández-Cardador, A.; Cucala, A.P. Assessment of energy-saving techniques in direct-current-electrified mass transit systems. Transp. Res. Part C Emerg. Technol. 2014, 38, 85-100. [CrossRef]

7. Lv, X.; He, B.; Li, Y. Inbound Energy-Saving Slope Design Method of High-Speed Railway. In Proceedings of the ICTE 2013: Safety, Speediness, Intelligence, Low-Carbon, Innovation, Chengdu, China, 19-20 October 2013.

8. Roch-Dupré, D.; Cucala, A.P.; Pecharromán, R.; López-López, Á.J.; Fernández-Cardador, A. Evaluation of the impact that the traffic model used in railway electrical simulation has on the assessment of the installation of a Reversible Substation. Int. J. Electr. Power Energy Syst. 2018, 102, 201-210. [CrossRef]

9. Roch-Dupré, D.; López-López, Á.J.; Pecharromán, R.R.; Cucala, A.P.; Fernández-Cardador, A. Analysis of the demand charge in DC railway systems and reduction of its economic impact with Energy Storage Systems. Int. J. Electr. Power Energy Syst. 2017, 93, 459-467. [CrossRef] 
10. Fernández-Rodríguez, A.; Fernández-Cardador, A.; Cucala, A.P.; Falvo, M.C. Energy Efficiency and Integration of Urban Electrical Transport Systems: EVs and Metro-Trains of Two Real European Lines. Energies 2019, 12, 366. [CrossRef]

11. Falvo, M.C.; Lamedica, R.; Bartoni, R.; Maranzano, G. Energy management in metro-transit systems: An innovative proposal toward an integrated and sustainable urban mobility system including plug-in electric vehicles. Electr. Power Syst. Res. 2011, 81, 2127-2138. [CrossRef]

12. Iannuzzi, D.; Pagano, E.; Tricoli, P.; Iannuzzi, D.; Pagano, E.; Tricoli, P. The Use of Energy Storage Systems for Supporting the Voltage Needs of Urban and Suburban Railway Contact Lines. Energies 2013, 6, 1802-1820. [CrossRef]

13. Arboleya, P.; Coto, M.; González-Morán, C.; Arregui, R. On board accumulator model for power flow studies in DC traction networks. Electr. Power Syst. Res. 2014, 116, 266-275. [CrossRef]

14. Beusen, B.; Degraeuwe, B.; Debeuf, P. Energy savings in light rail through the optimization of heating and ventilation. Transp. Res. Part Transp. Environ. 2013, 23, 50-54. [CrossRef]

15. Bombardier. Aeroefficient Optimised Train Shaping; Bombardier: Hennigsdorf, Germany, 2010.

16. Kondo, M.; Miyabe, M.; Manabe, S. Development of a High Efficiency Induction Motor and the Estimation of Energy Conservation Effect. Q. Rep. RTRI 2014, 55, 138-143. [CrossRef]

17. Matsuoka, K.; Kondo, M. Energy Saving Technologies for Railway Traction Motors. IEEJ Trans. Electr. Electron. Eng. 2014, 5, 278-284. [CrossRef]

18. Ichikawa, K. Application of Optimization Theory for Bounded State Variable Problems to the Operation of Train. Bull. JSME 1968, 11, 857-865. [CrossRef]

19. Howlett, P. An optimal strategy for the control of a train. J. Aust. Math. Soc. Ser. B 1990, 31, $454-471$. [CrossRef]

20. Howlett, P.G.; Pudney, P.J.; Vu, X. Local energy minimization in optimal train control. Automatica 2009, 45, 2692-2698. [CrossRef]

21. Liu, R.; Golovitcher, I.M. Energy-efficient operation of rail vehicles. Transp. Res. Part Policy Pract. 2003, 37, 917-932. [CrossRef]

22. Khmelnitsky, E. On an optimal control problem of train operation. IEEE Trans. Autom. Control 2000, 45, 1257-1266. [CrossRef]

23. Yang, X.; Li, X.; Ning, B.; Tang, T. A Survey on Energy-Efficient Train Operation for Urban Rail Transit. IEEE Trans. Intell. Transp. Syst. 2016, 17, 2-13. [CrossRef]

24. Albrecht, A.R.; Howlett, P.G.; Pudney, P.J.; Vu, X. Energy-efficient train control: From local convexity to global optimization and uniqueness. Automatica 2013, 49, 3072-3078. [CrossRef]

25. Su, S.; Li, X.; Tang, T.; Gao, Z. A Subway Train Timetable Optimization Approach Based on Energy-Efficient Operation Strategy. IEEE Trans. Intell. Transp. Syst. 2013, 14, 883-893. [CrossRef]

26. Yang, J.; Jia, L.; Lu, S.; Fu, Y.; Ge, J. Energy-Efficient Speed Profile Approximation: An Optimal Switching Region-Based Approach with Adaptive Resolution. Energies 2016, 9, 762. [CrossRef]

27. Albrecht, T.; Binder, A.; Gassel, C. Applications of real-time speed control in rail-bound public transportation systems. IET Intell. Transp. Syst. 2013, 7, 305-314. [CrossRef]

28. Ichikawa, S.; Miyatake, M. Energy Efficient Train Trajectory in the Railway System with Moving Block Signaling Scheme. IEEJ J. Ind. Appl. 2019, 8, 586-591. [CrossRef]

29. Lu, S.; Hillmansen, S.; Ho, T.K.; Roberts, C. Single-Train Trajectory Optimization. IEEE Trans. Intell. Transp. Syst. 2013, 14, 743-750. [CrossRef]

30. Miyatake, M.; Ko, H. Optimization of Train Speed Profile for Minimum Energy Consumption. IEEJ Trans. Electr. Electron. Eng. 2010, 5, 263-269. [CrossRef]

31. Miyatake, M.; Matsuda, K. Energy Saving Speed and Charge/Discharge Control of a Railway Vehicle with On-board Energy Storage by Means of an Optimization Model. IEEJ Trans. Electr. Electron. Eng. 2009, 4, 771-778. [CrossRef]

32. Gu, Q.; Tang, T.; Cao, F.; Song, Y. Energy-Efficient Train Operation in Urban Rail Transit Using Real-Time Traffic Information. IEEE Trans. Intell. Transp. Syst. 2014, 15, 1216-1233. [CrossRef]

33. Rodrigo, E.; Tapia, S.; Mera, J.; Soler, M. Optimizing Electric Rail Energy Consumption Using the Lagrange Multiplier Technique. J. Transp. Eng. 2013, 139, 321-329. [CrossRef] 
34. Wang, Y.; De Schutter, B.; van den Boom, T.J.J.; Ning, B. Optimal trajectory planning for trains-A pseudospectral method and a mixed integer linear programming approach. Transp. Res. Part C Emerg. Technol. 2013, 29, 97-114. [CrossRef]

35. Wang, Y.; De Schutter, B.; van den Boom, T.J.J.; Ning, B. Optimal trajectory planning for trains under fixed and moving signaling systems using mixed integer linear programming. Control Eng. Pract. 2014, 22, 44-56. [CrossRef]

36. Wong, K.K.; Ho, T.K. Coast control for mass rapid transit railways with searching methods. IEE Proc. Electr. Power Appl. 2004, 151, 365-376. [CrossRef]

37. De Cuadra, F.; Fernandez, A.; de Juan, J.; Herrero, M.A. Energy-Saving Automatic Optimisation of Train Speed Commands Using Direct Search Techniques; Wessex Institute of Technology: Southampton, UK, 1996; Volume 10.

38. Zhao, N.; Roberts, C.; Hillmansen, S.; Tian, Z.; Weston, P.; Chen, L. An integrated metro operation optimization to minimize energy consumption. Transp. Res. Part C Emerg. Technol. 2017, 75, 168-182. [CrossRef]

39. Tian, Z.; Weston, P.; Zhao, N.; Hillmansen, S.; Roberts, C.; Chen, L. System energy optimisation strategies for metros with regeneration. Transp. Res. Part C Emerg. Technol. 2017, 75, 120-135. [CrossRef]

40. Acikbas, S.; Soylemez, M.T. Coasting point optimisation for mass rail transit lines using artificial neural networks and genetic algorithms. IET Electr. Power Appl. 2008, 2, 172-182. [CrossRef]

41. Chuang, H.-J.; Chen, C.-S.; Lin, C.-H.; Hsieh, C.-H.; Ho, C.-Y. Design of Optimal Coasting Speed for MRT Systems Using ANN Models. IEEE Trans. Ind. Appl. 2009, 45, 2090-2097. [CrossRef]

42. Bocharnikov, Y.V.; Tobias, A.M.; Roberts, C. Reduction of train and net energy consumption using genetic algorithms for Trajectory Optimisation. In Proceedings of the IET Conference on Railway Traction Systems (RTS 2010), Birmingham, UK, 13-15 April 2010; pp. 1-5.

43. Carvajal-Carreño, W.; Cucala, A.P.; Fernández-Cardador, A. Optimal design of energy-efficient ATO CBTC driving for metro lines based on NSGA-II with fuzzy parameters. Eng. Appl. Artif. Intell. 2014, 36, 164-177. [CrossRef]

44. Domínguez, M.; Fernández-Cardador, A.; Cucala, A.P.; Gonsalves, T.; Fernández, A. Multi objective particle swarm optimization algorithm for the design of efficient ATO speed profiles in metro lines. Eng. Appl. Artif. Intell. 2014, 29, 43-53. [CrossRef]

45. Keskin, K.; Karamancioglu, A. Energy-Efficient Train Operation Using Nature-Inspired Algorithms. J. Adv. Transp. 2017, 2017, 12. [CrossRef]

46. Kim, Y.-G.; Jeon, C.-S.; Kim, S.-W.; Park, T.-W. Operating speed pattern optimization of railway vehicles with differential evolution algorithm. Int. J. Automot. Technol. 2013, 14, 903-911. [CrossRef]

47. Sicre, C.; Cucala, A.P.; Fernández, A.; Lukaszewicz, P. Modeling and optimizing energy-efficient manual driving on high-speed lines. IEEJ Trans. Electr. Electron. Eng. 2012, 7, 633-640. [CrossRef]

48. Yang, X.-S. Nature-Inspired Optimization Algorithms; Elsevier: Amsterdam, The Netherlands, 2014; ISBN 978-0-12-416745-2.

49. Chang, C.S.; Sim, S.S. Optimising train movements through coast control using genetic algorithms. Electr. Power Appl. IEE Proc. 1997, 144, 65-73. [CrossRef]

50. Lechelle, S.A.; Mouneimne, Z.S. OptiDrive: A Practical Approach for the Calculation of Energy-Optimised Operating Speed Profiles; IET: London, UK, 2010; p. 23.

51. Li, X.; Lo, H.K. An energy-efficient scheduling and speed control approach for metro rail operations. Transp. Res. Part B Methodol. 2014, 64, 73-89. [CrossRef]

52. Wong, K.K.; Ho, T.K. Dynamic coast control of train movement with genetic algorithm. Int. J. Syst. Sci. 2004, 35, 835-846. [CrossRef]

53. Wong, K.K.; Ho, T.K. Coast control of train movement with genetic algorithm. In Proceedings of the 2003 Congress on Evolutionary Computation, CEC '03, Canberra, Australia, 8-12 December 2003; Volume 2, pp. 1280-1287.

54. Yang, L.; Li, K.; Gao, Z.; Li, X. Optimizing trains movement on a railway network. Omega 2012, 40, 619-633. [CrossRef]

55. Wei, L.; Qunzhan, L.; Bing, T. Energy Saving Train Control for Urban Railway Train with Multi-population Genetic Algorithm. In Proceedings of the International Forum on Information Technology and Applications, IFITA '09, Chengdu, China, 15-17 May 2009; Volume 2, pp. 58-62. 
56. Huang, Y.; Ma, X.; Su, S.; Tang, T. Optimization of Train Operation in Multiple Interstations with Multi-Population Genetic Algorithm. Energies 2015, 8, 14311-14329. [CrossRef]

57. Bocharnikov, Y.V.; Tobias, A.M.; Roberts, C.; Hillmansen, S.; Goodman, C.J. Optimal driving strategy for traction energy saving on DC suburban railways. IET Electr. Power Appl. 2007, 1, 675-682. [CrossRef]

58. Cucala, A.P.; Fernández, A.; Sicre, C.; Domínguez, M. Fuzzy optimal schedule of high speed train operation to minimize energy consumption with uncertain delays and driver's behavioral response. Eng. Appl. Artif. Intell. 2012, 25, 1548-1557. [CrossRef]

59. Hwang, H.-S. Control strategy for optimal compromise between trip time and energy consumption in a high-speed railway. IEEE Trans. Syst. Man Cybern. Part Syst. Hum. 1998, 28, 791-802. [CrossRef]

60. Sicre, C.; Cucala, A.P.; Fernández-Cardador, A. Real time regulation of efficient driving of high speed trains based on a genetic algorithm and a fuzzy model of manual driving. Eng. Appl. Artif. Intell. 2014, 29, 79-92. [CrossRef]

61. Ke, B.-R.; Lin, C.-L.; Yang, C.-C. Optimisation of train energy-efficient operation for mass rapid transit systems. IET Intell. Transp. Syst. 2012, 6, 58-66. [CrossRef]

62. Yan, X.; Cai, B.; Ning, B.; ShangGuan, W. Online distributed cooperative model predictive control of energy-saving trajectory planning for multiple high-speed train movements. Transp. Res. Part C Emerg. Technol. 2016, 69, 60-78. [CrossRef]

63. Xie, T.; Wang, S.; Zhao, X.; Zhang, Q. Optimization of Train Energy-Efficient Operation Using Simulated Annealing Algorithm. In Intelligent Computing for Sustainable Energy and Environment; Li, K., Li, S., Li, D., Niu, Q., Eds.; Communications in Computer and Information Science; Springer: Berlin/Heidelberg, Germany, 2013; pp. 351-359. ISBN 978-3-642-37104-2.

64. Chevrier, R.; Pellegrini, P.; Rodriguez, J. Energy saving in railway timetabling: A bi-objective evolutionary approach for computing alternative running times. Transp. Res. Part C Emerg. Technol. 2013, 37, $20-41$. [CrossRef]

65. Fernández-Rodríguez, A.; Fernández-Cardador, A.; Cucala, A.P.; Domínguez, M.; Gonsalves, T. Design of Robust and Energy-Efficient ATO Speed Profiles of Metropolitan Lines Considering Train Load Variations and Delays. IEEE Trans. Intell. Transp. Syst. 2015, 16, 2061-2071. [CrossRef]

66. Fernández-Rodríguez, A.; Fernández-Cardador, A.; Cucala, A.P. Balancing energy consumption and risk of delay in high speed trains: A three-objective real-time eco-driving algorithm with fuzzy parameters. Transp. Res. Part C Emerg. Technol. 2018, 95, 652-678. [CrossRef]

67. Fernández-Rodríguez, A.; Fernández-Cardador, A.; Cucala, A.P. Real time eco-driving of high speed trains by simulation-based dynamic multi-objective optimization. Simul. Model. Pract. Theory 2018, 84, 50-68. [CrossRef]

68. Douglas, H.; Roberts, C.; Hillmansen, S.; Schmid, F. An assessment of available measures to reduce traction energy use in railway networks. Energy Convers. Manag. 2015, 106, 1149-1165. [CrossRef]

69. Albrecht, A.; Howlett, P.; Pudney, P.; Vu, X.; Zhou, P. The two-train separation problem on non-level track-Driving strategies that minimize total required tractive energy subject to prescribed section clearance times. Transp. Res. Part B Methodol. 2018, 111, 135-167. [CrossRef]

70. Coleman, D.; Howlett, P.; Pudney, P.; Xuan, V.; Yee, R. Coasting Boards vs. Optimal Control; IET: London, UK, 2010; pp. 1-5.

71. Franke, R.; Terwiesch, P.; Meyer, M. An algorithm for the optimal control of the driving of trains. In Proceedings of the 39th IEEE Conference on Decision and Control, Sydney, NSW, Australia, 12-15 December 2000; Volume 3, pp. 2123-2128.

72. Johnson, P.; Brown, S. A simple in-cab schedule advisory system to save energy and improve on-time performance. In Proceedings of the IET Conference on Railway Traction Systems (RTS 2010), Birmingham, UK, 13-15 April 2010; p. 15.

73. Scheepmaker, G.M.; Goverde, R.M.P. The interplay between energy-efficient train control and scheduled running time supplements. J. Rail Transp. Plan. Manag. 2015, 5, 225-239. [CrossRef]

74. González-Gil, A.; Palacin, R.; Batty, P.; Powell, J.P. A systems approach to reduce urban rail energy consumption. Energy Convers. Manag. 2014, 80, 509-524. [CrossRef]

75. Pudney, P.; Howlett, P. Optimal driving strategies for a train journey with speed limits. ANZIAM J. 1994, 36, 38-49. [CrossRef] 
76. Domínguez, M.; Fernández, A.; Cucala, A.P.; Cayuela, L.P. Computer-aided design of ATO speed commands according to energy consumption criteria. WIT Trans. Built Environ. 2008, 103, 183-192.

77. Dominguez, M.; Fernandez, A.; Cucala, A.P.; Blanquer, J. Efficient Design of Automatic Train Operation Speed Profiles with On Board Energy Storage Devices. WIT Trans. Built Environ. 2010, 114, 509-520.

78. Coello, C.A.C.; Pulido, G.T.; Lechuga, M.S. Handling multiple objectives with particle swarm optimization. IEEE Trans. Evol. Comput. 2004, 8, 256-279. [CrossRef]

79. Scheepmaker, G.M.; Goverde, R.M.P. Energy-efficient train control including regenerative braking with catenary efficiency. In Proceedings of the 2016 IEEE International Conference on Intelligent Rail Transportation (ICIRT), Birmingham, UK, 23-25 August 2016; pp. 116-122.

80. Falvo, M.C.; Sbordone, D.; Fernández-Cardador, A.; Cucala, A.P.; Pecharromán, R.R.; López-López, A. Energy savings in metro-transit systems: A comparison between operational Italian and Spanish lines. Proc. Inst. Mech. Eng. Part F J. Rail Rapid Transit 2016, 230, 345-359. [CrossRef]

81. Chang, C.S.; Xu, D.Y.; Quek, H.B. Pareto-optimal set based multiobjective tuning of fuzzy automatic train operation for mass transit system. Electr. Power Appl. IEE Proc. 1999, 146, 577-583. [CrossRef]

82. Chang, C.S.; Xu, D.Y. Differential evolution based tuning of fuzzy automatic train operation for mass rapid transit system. Electr. Power Appl. IEE Proc. 2000, 147, 206-212. [CrossRef]

83. Wang, Y.; Ning, B.; Cao, F.; De Schutter, B.; van den Boom, T.J.J. A survey on optimal trajectory planning for train operations. In Proceedings of the 2011 IEEE International Conference on Service Operations, Logistics and Informatics, Beijing, China, 10-12 July 2011; pp. 589-594.

(C) 2020 by the authors. Licensee MDPI, Basel, Switzerland. This article is an open access article distributed under the terms and conditions of the Creative Commons Attribution (CC BY) license (http://creativecommons.org/licenses/by/4.0/). 